\title{
El viaje del zorro al cielo y su tío el tigre: Texturas transculturales amerindias en dos repertorios de relatos mapuche del zorro'
}

The fox's journey to heaven and his uncle the tiger: Amerindian cross-cultural textures in two repertoires of Mapuche tales of the fox

\author{
RODRigo Moulian \\ Universidad Austral de Chile, Chile \\ Jaqueline Caniguan \\ Universidad de La Frontera, Chile \\ Gonzalo EsPino \\ Universidad Nacional Mayor de San Marcos, Perú
}

\begin{abstract}
RESUMEN El artículo muestra los contenidos transculturales amerindios en dos repertorios de relatos mapuche del zorro. El primero de ellos corresponde al viaje del zorro al cielo, originario del área centro andina. El segundo es el del zorro y su tío el tigre procedente de las narrativas del Chaco. A través de un análisis narratológico, se destaca la recurrencia de los motivos que estructuran las tramas narrativas y dan forma a los relatos. Al respecto argumentamos que la representación del zorro como un personaje transgresor, común en las narrativas, expresa un problema general, por lo mismo, proclive a su simbolización transcultural. Las contradicciones en la conducta del zorro exponen las tensiones entre las necesidades básicas y los impulsos vitales del personaje y las normas culturales para la administración de las mismas, lo que constituye una experiencia común a la condición humana.
\end{abstract}

PALABRAS CLAVE Zorro; narrativas; transculturalidad; transgresiones; mapuche.

1. El artículo presenta resultados del proyecto Fondecyt 1160388, Translingüística, supralingüística e interculturalidad: un estudio de casos de correlaciones en constelaciones semióticas centro y sur andinas indicadoras de co-tradición. 


\begin{abstract}
This paper shows the Amerindian cross-cultural contents of two repertories of Mapuche tales of the fox. The first one corresponds to a fox's journey to heaven, originated in Central Andean area. The second one is about a fox and his uncle, the tiger, taken from Chaco narratives. Through a narratological analysis, it stands out the recurrence of the motives that give form to the tales. In relation to that, we argue that the representation of the fox as a trickster, common to these narratives, expresses a general problem, propitious for cross cultural representation. The contradiction in the fox's behavior exposes the tension between basic necessities and vital impulses, and the cultural norms to conform them, which constitutes a common experience of human condition.
\end{abstract}

KEYWORDS Fox, narratives; cross-culture; transgressions; Mapuche.

\title{
Introducción
}

El ciclo narrativo del zorro tiene un lugar destacado en la literatura oral mapuche. Lenz (1895-1897, p. 179) lo considera «el personaje predilecto de la fábula araucana»; Salas (1992a, p. 285) lo califica como «personaje omnipresente» en los cuentos de matriz originaria. El ngürü, como se designa al zorro en mapudungun, es el protagonista con mayor representatividad dentro de los relatos animalísticos, que constituyen uno de los géneros predominantes de la narrativa mapuche (Lenz, 1895-1897a; Slater, 1979a, 1988; Salas, 1992a). Estos relatos de ficción, denominados epew, se caracterizan por la antropomorfización de las especies animales. Los personajes presentan entre ellos relaciones de consanguinidad o afinidad y asumen diversos roles sociales que implican obligaciones y derechos, pero manifiestan, de modo implícito, las posiciones antagónicas propias de la escala trófica, por su condición de competidores dentro de su nicho ecológico o por su relación cazador-presa. La figura del zorro presenta, frecuentemente, en estos relatos la función narrativa de trickster o tramposo (Radin, 1956). El ngürü emplea su ingenio para engañar y vencer a animales mayores con los que mantiene relaciones de parentesco o compadrazgo, pero se muestra inoperante ante animales menores que lo burlan y lo dejan - parafraseando a van Kessel (1993)en condición de «tramposo engañado».

Salas (1992a) señala que el propósito primario de este género de relatos es la entretención, pero destaca que ellos constituyen, igualmente, medios de transmisión cultural, en tanto reproducen contenidos y valores mapuche. Golluscio (2006) le reconoce al epew un carácter lúdico-humorístico, pero enfatiza su función socializadora. Caraballo (2012) considera las prácticas narrativas como manifestaciones de la identidad cultural, en tanto, los relatos son portadores de contenidos cosmovisionarios. Para esta autora, los epew son una forma de narrar 
la cosmovisión. Esta valoración respecto del carácter ejemplar de los contenidos de los relatos, a nuestro entender, resulta problemática por el modo como se configura este universo narrativo. En primer término, porque el argumento de los relatos aborda la competencia en ingenio y habilidad de las especies animales exponiendo la contradicción entre las normas culturales y los antagonismos naturales. En segundo lugar, porque la función del trickster consiste en la transgresión de las normas culturales, que se ven socavadas por la acción del protagonista. Como advierte Foote (2012, p. 194), «desde un comienzo, el zorro no obedece ninguna ley; es un continuo transgresor». El problema normativo que ello plantea se resuelve en muchos relatos a través de una coda o cierre didáctico, similar a la moraleja de las fábulas (Salas, 1984), donde el transgresor es castigado por su mal comportamiento. El cuento opera, entonces, dentro de un canon socializador.

No obstante, ello no siempre es así, porque los epew no presentan una estructura narrativa fija, sino se encuentran abiertos a una continua reactualización, que modifica sus componentes (Slater, 1979a). Versiones de un mismo relato producidas por diversos narradores contienen importantes variantes, que dependen del sujeto de la enunciación y las condiciones del contexto. Lo mismo sucede en distintas versiones de un mismo narrador. Como expresión de ello, con frecuencia los cuentos carecen de la coda didáctica y las transgresiones del zorro quedan sin sanción. El protagonista sale triunfante en sus intereses pese a haber violado principios básicos del admapu, como se denomina al sistema normativo mapuche. De este modo, los modelos culturales se destacan en la contravención de sus límites, la excepción es aquí la regla. En términos pragmáticos, el código de recepción de estos relatos es humorístico. Así lo advierte Golluscio (2006), quien destaca que el epew se codifica como un discurso de doble sentido. En nuestra experiencia, la sola mención a las andanzas del zorro hace despertar una sonrisa en el rostro de los destinatarios. Sus acciones no son tomadas en serio, sino como hechos inverosímiles, propios del mundo de la ficción, cuyo contrasentido provoca hilaridad. Golluscio (2006) reivindica la función socializadora de estas expresiones hilarantes, por su carácter expansivo y liberador. En nuestra perspectiva, ello no deja de resultar paradojal, porque el doble sentido se define por su ambivalencia.

En algunos relatos transgresores paradigmáticos, el problema de la selección de los contenidos destinados para provocar la risa se relativiza si se analiza el origen de los mismos. Es el caso de la serie narrativa de «el viaje del zorro al cielo» que procede del área centroandina (Morote, 1988) y de la serie narrativa de «el zorro y su tío el tigre» que se encuentra ampliamente registrada entre los pueblos originarios del Chaco (Terán, 1999; Wilbert y Simoneau, 1982, 1988, 1989) y en los relatos folclóricos del noroeste argentino (NOA). Por lo mismo, las contradicciones culturales que ellos expresan no se pueden considerar como la expresión de conflictos específicos 
y propios de la sociedad mapuche. Ellos exponen un ejercicio reflexivo compartido que, como advierte La Riva (2005), manifiesta las contradicciones entre las normas culturales y los impulsos naturales. En el contexto mapuche, la gravedad del asunto se resuelve tomándose con sentido del humor esta narrativa, que tan bien expresa las contradicciones de la condición humana.

En este artículo argumentamos que el análisis de estos relatos debe hacerse considerando el carácter transcultural de los mismos. Ellos muestran procesos de circulación ampliada de las expresiones narrativas amerindias que se ven reproducidas y reapropiadas en diversos contextos culturales. En ellos se encuentran tramas narrativas y contenidos que no se originan en el espacio mapuche, pero que se modifican y adaptan a la cultura local. Su análisis debe hacerse considerando los procesos de reproducción mimética, re-creación y ajuste a la cultura mapuche, en el marco de un proceso de circulación extenso. Como advierte Espino (2014), los cuentos se muestran aquí como dispositivos comunicativos transculturales, que rebasan los límites de las lenguas y las culturas.

\section{Aspectos teóricos y metodológicos}

El concepto de «transculturación» fue acuñado por el sociólogo cubano Ortiz (1987, p. 93 [1940]) para designar los «variadísimos fenómenos» implicados en las «transmutaciones de culturas». Si bien esta noción se elabora para el análisis de los procesos que conforman la cultura cubana, su autor reivindica su carácter teórico, que se propone como alternativa al concepto de «aculturación». Este último, elaborado por la antropología anglosajona, designa a la adquisición de elementos culturales ajenos. De acuerdo a Ortiz, el cambio cultural no supone un simple traspaso de contenidos desde una cultura donadora a una receptora. El proceso implica siempre una «desculturación» o pérdida de elementos de la cultura donante, la «inculturación» o adquisición de componentes de la cultura receptora y procesos de «neoculturación» o generación de nuevos fenómenos culturales. Para el autor, la transculturación es un proceso creativo que comprende estos tres aspectos. En sus palabras (1987, p. 96 [1940]): «Entendemos que el vocablo transculturación expresa mejor las diferentes fases del proceso transitivo de una cultura a otra, porque éste no consiste simplemente en adquirir una distinta cultura [...]».

Como advierte Malinoswki en la introducción a la obra de Ortiz (1987, p. 4 [1940]), el concepto alude a «todo cambio de cultura» que se produce en una situación de contacto. El antropólogo polaco destaca las virtudes de este término (1987, p.5 [1940]) «que no contiene la implicación de una cierta cultura a la cual tiene que tender otra». Por el contrario, el concepto de transculturación implica «una transición entre dos culturas, ambas activas, ambas contribuyentes, con sendos aportes, ambas cooperantes al advenimiento de una nueva realidad». Se trata, por lo tanto, de un concepto descriptivo, que alude al proceso de combinación de elementos en las 
dinámicas de transformación cultural. Como apunta Guanche (1995, p. 3), éste nos ofrece «una concepción generalizadora de los cambios cualitativos en una cultura».

La noción ha sido puesta en uso predominantemente para el análisis de los procesos de cambio cultural en situaciones de colonialidad y dependencia metropolitana. No obstante, la misma caracteriza los procesos de cambio cultural de un modo abstracto, por lo que es aplicable a diversos contextos sociales. El propio Ortiz (1987, p. 93 [1940]) alude a la «transculturación del indio paleolítico al neolítico» para caracterizar los procesos de evolución cultural prehispánicos. Del mismo modo, denomina «transculturación indoafricana» (1987, p. 215 [1940]) a la mutua interdigitación de cambios entra la población nativa y los esclavos negros. En tanto, la apropiación del uso del tabaco en África Central es signada por el sociólogo cubano como la «transculturación del tabaco entre los negros» (1987, p. 215). Millington (2007, p. 264) destaca que el concepto se puede aplicar para caracterizar los procesos de transformación cultural en diversos contextos espaciales y temporales: «donde las personas y las culturas se han encontrado e interactuado lógicamente la transculturación habrá ocurrido de tiempo en tiempo». En opinión del mismo autor, esto «debe haber sido una virtual constante de vuelta a la prehistoria».

Rama (1974, 2008 [1984]) lleva el concepto de transculturación al campo de la narrativa, mostrando que este proceso no opera sólo a partir del contacto intercultural directo, sino también a través de la mediación de los textos. De acuerdo al autor, ello se expresa en los planos de la lengua, la estructura literaria y la cosmovisión expuesta en los contenidos de las obras. Para Rama, el proceso de transculturación contiene cuatro operaciones distintivas: pérdidas, selecciones, redescubrimientos e incorporaciones. Al respecto nos dice: «Estas operaciones son concomitantes y se resuelven todas dentro de una reestructuración general del sistema cultural, que es la función creadora más alta» (2008, p. 47). A nuestro entender, dos son los énfasis diferenciadores del tratamiento del concepto transculturación en Rama. El primero es la importancia que le da a la selectividad de los elementos culturales que participan de estos procesos, tanto en términos de las operaciones que realiza la cultura donante como de los intereses y condiciones de la cultura receptora. El segundo, la relevancia que le asigna a la reestructuración de los elementos incorporados en la cultura receptora, lo que denomina el «ars combinatorio» (2008, p. 46) y caracteriza como un proceso inventivo.

En esta perspectiva, los fenómenos transculturales son el resultado de los procesos de transculturación, que permiten la difusión de recursos en diversos contextos sociales. Fenomenológicamente, ello se expresa en la recurrencia de prácticas, componentes materiales o elementos simbólicos que muestran semejanza de forma y contenido, que indican un origen común. En el presente trabajo, nuestro objeto de estudio son las «texturas transculturales» en dos repertorios narrativos mapuche. Los 
casos de estudio son los relatos de «el viaje de zorro al cielo», que tiene su origen en la tradición oral centro andina, y las variantes de «el zorro y su tío el tigre» o «el zorro y el león» que nos remiten a las narrativas originarias del Chaco. Dado nuestro interés por los procesos de transculturación, se han incorporado al análisis, igualmente, algunos relatos tehuelche, por su convivencia en el espacio geográfico de la Patagonia con los mapuche. En el primer caso de estudio se ha analizado un corpus compuesto por once relatos mapuche y dos tehuelche. En el segundo caso se ha estudiado un corpus de veintitrés relatos. Nueve de ellos corresponden a la serie «el zorro y su tío el tigre»: siete de ellos mapuche, dos tehuelche. En tanto, otros catorce corresponden a la serie del zorro y el león. Estos repertorios se configuran a través de una búsqueda sistemática de ejemplares textuales en las principales fuentes de relatos mapuche y en las fuentes disponibles de relatos tehuelche.

Empleamos un análisis narratológico (Reis y Lopes, 1996) para el estudio de estos repertorios, con el propósito de identificar contenidos transculturales en la textura de los relatos. Para este fin, analizamos las unidades de contenido que organizan los relatos en diversos niveles de complejidad: desde los «motivos» como unidad mínima a la «trama» como unidad argumental y sus principios de adscripción. Como categorías de análisis empleamos la noción de «ciclo narrativo» para designar al conjunto de relatos que cuentan diversos tipos de historias protagonizadas por un mismo personaje o personajes. La noción de «serie narrativa» designa aquí al conjunto de variantes de una historia protagonizada por el o los mismos personajes. La noción de «episodio» denota a los segmentos narrativos relativamente autónomos que forman parte del plan o estructura textual de cada uno de los relatos. Por «secuencia narrativa» entendemos al agrupamiento cohesionado de acciones narrativas que componen los episodios. Por «acción narrativa» designamos a las distintas actividades que desarrolla el personaje, las que se organizan en secuencias, que a su vez conforman los episodios. En el nivel componencial mínimo, entendemos que los «motivos» son las unidades de contenido básico que estructuran las acciones, organizan las secuencias narrativas, episodios, incluso «tramas». Con este último concepto designamos a los argumentos o historias que organizan la estructura narrativa a partir de diversos conflictos o nudos narrativos.

Para el análisis comparativo de los contenidos narrativos se han empleado los estudios preexistentes del motivo del viaje del zorro al cielo en la literatura oral andina (Espino, 2014; Itier, 1997; Morote, 1988) y las compilaciones de relatos de la etnoliteratura del Chaco (Wilbert y Simoneau, 1982, 1985, 1988, 1989), que identifican los motivos dominantes en los textos. 


\section{El zorro que va al cielo}

El ciclo narrativo del zorro tiene un lugar prominente en la literatura oral andina (Andreani, 2014; Espino, 2014; van Kessel, 1994). En un trabajo de referencia básico sobre el tema, Morote (1988 [1955]) identifica veinte motivos literarios que componen las tramas narrativas del zorro, varios de los cuales se expresan, igualmente, en los relatos que circulan en el mundo mapuche. Entre ellos «el zorro aprende a silbar», «el cadáver que echa vientos», «la apuesta para resistir el frío». Por su recurrencia, complejidad y contenidos culturales el «viaje del zorro al cielo» es el más relevante de estos motivos. Se trata de un tema ampliamente representado en las narrativas del área centro sur andina (Itier, 1997; La Riva, 2005; Morote, 1988), al punto que Itier (2007) señala que es uno de los relatos que figuran con mayor frecuencia en los repertorios de cuentos andinos. Su centro de difusión es el área puneña, de tierras altas, y los valles costeros colindantes, donde registra profundidad histórica, amplia dispersión y codificación múltiple. Versiones de este relato circulan en lengua quechua en la zona central y sur de Perú (Itier, 1999), sur de Bolivia (Jemio, 2011); en lengua aymara en el área central y norte de Bolivia (Alegría, 2014; Arnold, Jiménez y Yapita 2014; Jemio, 2005) y sur de Perú. En castellano se registran en el área atacameña (Lehnert, 2000) y en el noroeste de Argentina (Chertudi, 1965; Palleiro, 1998; Vidal de Battini, 1980). Si bien los relatos en lenguas vernáculas muestran la interferencia de elementos hispanos (Itier, 2007; Morote, 1988), la trama narrativa expresa, igualmente, componentes míticos de los pueblos originarios, como destacan el propio Morote (1988 [1955]) y Tomoeda (1982).

La estructura del relato se compone esquemáticamente de las siguientes secuencias narrativas: i) el zorro se entera de que habrá una fiesta en el cielo, ii) el zorro le solicita a un ave, generalmente a un cóndor, que lo conduzca al cielo, iii) el cóndor exige el compromiso del zorro respecto a su buen comportamiento en el cielo, iv) una vez llegado al cielo el zorro rompe su compromiso y manifiesta un comportamiento desmesurado en la comida, la bebida, el canto, el baile y los empeños amorosos, v) el cóndor abandona al zorro, vi) para regresar a su residencia en la tierra, el zorro elabora un lazo con fibras vegetales, vii) cuando va descendiendo, el zorro insulta a unos pájaros, generalmente loros, que se cruzan en su camino, viii) los loros cortan la cuerda que sostiene al zorro; ix) el zorro muere destrozado al caer a tierra, $\mathrm{x}$ ) de los restos corporales del zorro se distribuyen y reproducen las semillas de las plantas que el animal había consumido en el cielo.

Como toda serie narrativa, los ejemplares textuales exponen una serie de variantes. Por ejemplo, el argumento del viaje del zorro al cielo se encuentra precedido de un segmento narrativo que presenta el motivo de la mujer adúltera (Itier, 1997), que también se enuncia de manera autónoma. En este relato, el zorro tiene relaciones sexuales con una mujer casada a la que ha ayudado previamente en sus labores 
agrícolas. Al llegar el marido, los amantes se encuentran en pleno acto, por lo que el zorro debe cortarse el pene para huir de la escena. Tras recuperar su órgano sexual, inicia su viaje al cielo. En las diversas versiones de los relatos, los motivos presentan transformaciones, pero la estructura narrativa se mantiene estable. Entre los desenlaces alternativos se encuentran la muerte del zorro, sin consecuencias posteriores, y la reproducción de la propia especie a partir de sus restos. No obstante, el desenlace que presenta mayor frecuencia es el de la difusión de las plantas. Por lo mismo, el canon interpretativo considera a este relato como un motivo mítico de carácter etiológico (Espino, 2014; Itier, 1997; Morote, 1988 [1955]; Rubina, 2012; Tomoeda, 1982).

El motivo de la cuerda que conecta la tierra y el cielo y el del viaje del zorro al cielo también forman parte de otros relatos que circulan en el área andina como «el zorro, hijo de Dios» (Valderrama y Escalante, 1997), «el zorro y la luna» (Vienrich, 1999), «las estrellas, el zorro y la simpa» (Ayala, 2002). En el primer texto, el zorro, hijo de Dios, es expulsado del cielo por su padre debido a su mal comportamiento. Durante su descenso a través de una cuerda, ofende a los loros, que cortan el lazo. En el segundo relato, el zorro quiere conocer a la luna. Sube al cielo a través de una cuerda, pero su desavenencia con el loro lo tumba al suelo. En el tercer relato, un hombre baja desde el cielo a través de una cuerda, luego de haber seguido hasta allí a una estrella. El mismo medio emplea el zorro para transitar entre los mundos, hasta que se encuentra con el loro.

La recurrencia de estos motivos muestra su inscripción en el imaginario narrativo andino. Su arraigo cultural queda de manifiesto en la presencia de los mismos en el arte rupestre (Fosa, 2019). Una representación del cóndor jalando hacia el cielo al zorro se encuentra en geoglifos de la cultura paracas. La imagen del zorro cayendo de cielo al lado de un cóndor se registra en los geoglifos de la cultura nazca. En términos temporales, los desarrollos civilizatorios a los que adscriben estos diseños se sitúan entre los años $700 \mathrm{AC}$ y $200 \mathrm{DC}$, el primero, y entre el 100 y 800 DC, el segundo. Ambas culturas se gestan en la costa y valles occidentales de lo que hoy constituye el Departamento de Ica, al sur del Perú. Imágenes del zorro subiendo y bajando por una cuerda se encuentran en los petroglifos de Toro Muerto, Arequipa, cuya ocupación data desde el período intermedio 800 al 1000 DC hasta el prehispánico tardío 1400 DC.

En las culturas andinas el zorro es considerado un mediador entre la tierra y el cielo. Su figura se identifica con una de las constelaciones oscuras de la Vía Láctea, situada próxima a la Constelación de la Llama (Urton, 1981). El inca Garcilaso de la Vega (2012 [1609]) consigna un relato ancestral que atribuye las manchas de la luna a sus amoríos con el zorro. Como el perro de los apus o achachilas, identifican a este cánido los pastores andinos. Con ello señalan la afinidad del zorro con los 
espíritus encarnados en las montañas sagradas de los pueblos quechua y aymara. Por lo mismo, los habitantes de la puna lo tratan con respeto, denominándolo «niñito»o «compadre» (Itier, 1997) cuando se tienen que referir a él. Su figura, no obstante, es ambigua (Alegría, 2014), por su rol de trickster (Morgante, 2001) o embustero. La Riva (2005) le atribuye a su carácter trasgresor un rol de mediador entre la naturaleza y la cultura. Sus apetitos e impulsividad le impiden someterse a las normas. Así también ocurre en el contexto cultural mapuche.

Hemos analizado doce versiones escritas del viaje del zorro al cielo. Once de ellas son mapuche (Caniuman, 2015, sp; Fundación Pehuén 2001a, sp; LehmannNitsche, 2013a, pp. 121-123; Lenz,1895-1897d, pp. 210-219; Lincopán, 2017, pp. 6592; Martínez y Loncón, 1999a, pp. 25-27; Painén, 1986a, pp. 101-107; Pino, 2017a, pp. 63-64; 2017b, pp. 64-65; Salas, 1992c, pp. 305-315; Tren Tren Mapu, 2001, sp) y una versión corresponde a la narrativa tehuelche (Bórmida y Siffredi, 1969-1970a, pp. 199-245). En diez de los casos, este tópico es el motivo estructurante de los relatos. En dos, se trata de episodios dentro de estructuras narrativas organizadas en torno a la relación del zorro y su tío el tigre (Lenz, 1895-1897d, pp. 210-219; Lehmann-Nitsche, 2013a, pp. 121-123). Siete de los relatos presentan transcripciones en mapudungun. Las excepciones son las versiones de Painén (1986a), Pino (2017a, 2017b), Caniuman (2015) y la de Bórmida y Siffredi (1969-1970a) que es un texto tehuelche, registrado en castellano.

Elementos narrativos constantes en este repertorio son el viaje del zorro al cielo, el uso de una cuerda como medio de descenso, la caída del zorro y su consecuente muerte o grave invalidez como resultado de ello. Elementos narrativos frecuentes -pero que admiten excepciones- son la presencia coprotagónica de un ave que conduce al zorro al cielo, la existencia de una fiesta en este espacio que motiva el viaje, el abandono del zorro en el cielo por parte de su compañero de viaje. Entre los motivos propios del modelo narrativo central andino ausentes en las versiones meridionales se cuentan el conflicto entre el zorro y el loro que le corta la cuerda y la difusión de las semillas de los alimentos a partir de la muerte del zorro. En contraste, las versiones australes muestran la incorporación de motivos propios de las culturas locales. En la narrativa mapuche, el empleo de un ritual chamánico denominado machitun para revivir al zorro. En el ejemplar tehuelche, la interacción con los habitantes del mundo de arriba que no comen ni defecan. Adicionalmente el repertorio registra un motivo ancestral panandino que no se encuentra en el modelo de referencia: la "cabeza almácigo», cubierta de flores tras la muerte del zorro, en la que se expresa una concepción vitalizada de este órgano corporal, que se considera contenedor del espíritu (Moulian y Poblete, 2018).

Los epew analizados muestran la contextualización narrativa del viaje del zorro al cielo en el mundo mapuche. En seis versiones el motivo del viaje es un ritual 
comunitario mapuche denominado sucesivamente ngillatun (Martínez y Loncón, 1999a, p. 21; Tren Tren Mapu, 2001, p. 24) o kamarikun (Lincopán, 2017; Salas, 1992c, p. 310) que designa una «ceremonia de agradecimiento»; futa trawün (LehmannNitsche, 2013a, p. 122), "gran reunión» y trawün (Fundación Pehuén, 2001a, p. 6) «junta». Se trata de etnónimos alternativos que designan las congregaciones rituales religiosas ancestrales. Su finalidad es propiciar la satisfacción de las necesidades colectivas a través de la entrega de ofrendas a las divinidades. Otra de las versiones nos sitúa implícitamente en un ámbito ritual a través de las referencias alimentarias. El zorro viaja al cielo para comer abundantemente carne. En el contexto mapuche éste no es un alimento cotidiano sino uno reservado para instancias ceremoniales o momentos especiales. Esto también se registra en otra versión donde el zorro viaja a un entierro en el cielo motivado por su deseo de «comer carne» (Caniuman, 2015, sp). Todos los relatos previamente referidos sitúan la acción en el espacio simbólico intracultural. La única excepción es el cuento titulado «El casamiento en el cielo» en el que el novio es «un español» (Pino, 2017a, p. 63).

Una particularidad de la serie narrativa mapuche es que el desenlace del relato se encuentra mediado por un segundo momento ritual, de carácter chamánico, que permite la resurrección del zorro. En siete versiones del cuento interviene un machi o chamán mapuche para restaurar al ngürü cuyo cuerpo se encuentra desbaratado luego de su caída del cielo (Caniuman, 2015; Lehmann-Nitsche, 2013a; Lincopán, 2017; Martínez y Loncón, 1999a; Painén, 1986a; Salas, 1992c; Tren Tren Mapu, 2001). Esta es una de las diferencias respecto del canon narrativo andino, donde el zorro muere, para dar lugar a la difusión de las semillas de los alimentos. En ninguno de los relatos meridionales se encuentra presente este motivo etiológico, lo que supone una transformación del modelo narrativo. El canon narrativo mapuche del viaje del zorro al cielo se orienta a la afirmación de la institucionalidad chamánica y su poder de devolverle la vida al zorro.

El esquema del relato se mueve entre dos instancias rituales emplazadas en un marco comunitario animalístico: un kamarikun / ngillatun o rogativa que motiva el viaje al cielo del zorro y un machitun, ritual chamánico de sanación realizado por sus pares para revitalizar al protagonista. Por lo mismo, el repertorio es rico en contenidos simbólicos y constituye un medio de reproducción social de la cultura mapuche. Algunos ejemplares narrativos recrean detalladamente los protocolos ceremoniales, refieren a los códigos de comportamiento, roles sociales propios del ritual y presentan el campo de relaciones y valores sociales que sustenta estas prácticas. Un relato pedagógico ejemplar es el que presenta Lincopán (2017) respecto del kamarikun. Los epew que relatan Painén (1986a) y Salas (1992c) ofrecen retratos sucintos, pero ricos en antecedentes simbólicos del machitun. 
Este universo narrativo constituye un marco paradigmático a partir del que se puede evaluar la conducta del zorro a la luz de las normas rituales y códigos sociales prevalecientes en él. Al respecto, se debe destacar que una constante en los epew son las transgresiones de su protagonista, que tensionan la función socializadora del relato. El zorro no se adecúa a las normas culturales. En ocasiones, las viola de manera flagrante, cometiendo faltas graves a los principios del admapu, como se denomina a las normas de la vida mapuche, sin recibir necesariamente una sanción por ello. En otras, sufre un infortunio momentáneo, que se puede tener como justo castigo, pero finalmente resulta redimido.

El zorro transgrede de manera recurrente los protocolos rituales. Por ejemplo, éste olvida que asiste al cielo en calidad de acompañante de un invitado ritual y que carece, por lo tanto, de una condición que justifique en propiedad su participación en este espacio. El jote, primo del zorro, es su patrocinante y encargado de conducirlo al cielo en cinco relatos (Caniuman, 2015; Lincopán, 2017; Martínez y Loncón, 1999a; Pino, 2017a; Tren Tren Mapu, 2001). Este rol es asumido por el cóndor en un epew (Fundación Pehuén, 2001a) y por la bandurria en otro (Lehmann-Nitsche, 2013a). Sus posibilidades de participación en las ceremonias se encuentran limitadas por este rol subsidiario y restringidas al tiempo de permanencia de quien lo invita. Contrariando su obligación, el zorro se desentiende de sus acompañantes y se queda en el cielo, tras la partida de estos. De su desatención se origina el problema del retorno a la tierra, que lo fuerza a intentar bajar a través de una cuerda, piola o rama de voqui, enredadera nativa. En este contexto se produce su caída.

En algunas versiones, las transgresiones son más explícitas. Al zorro se le pide que tenga cuidado en respetar los protocolos sociales al momento del saludo del longko (autoridad ancestral) anfitrión, pero éste se le adelanta y no lo deja hablar (Lincopán, 2017). El zorro se burla de su patrocinante cuando éste canta al presentarse en el cielo y le produce tristeza (Tren Tren Mapu, 2001). El zorro se hace llamar tripay antü, «salida del sol», dándose atributos simbólicos inmerecidos (Fundación Pehuén, 2001a). En una de las variantes que transcurre fuera del contexto ritual, desatiende las recomendaciones de su anfitrión en el cielo y lo hace enfadar (Pino, 2017b). Por borracho (Caniuman, 2015; Lincopán, 2017; Tren Tren Mapu, 2001) o enamorado (Martínez y Loncón, 1999a), el zorro se olvida de sus patrocinantes en el ritual. A su favor, podemos decir que el zorro no es el único que transgrede los códigos del admapu. En uno de los relatos que registra Pino (2017a), su primo el jote falta a su deber de darle sepultura y hacerle funeral tras su caída del cielo y se come su cadáver.

El destino trágico del zorro, que se precipita en su intento de retorno a la tierra y muere desbaratado, es consecuencia de este comportamiento desaprensivo. No obstante, la compasión y solidaridad de los miembros de su entorno social permiten su retorno a la vida. En tres versiones (Caniuman, 2015; Lincopán, 2017; Painén, 
1986a) es el jote el que llama a las machi (chamanes) representadas en formas de bandurria o raki. En un relato (Salas, 1992c), son los deudos no identificados del zorro los que convocan al agente médico-religioso. En dos relatos es iniciativa de las propias machi bandurrias revivir al muerto (Lenz, 1895-1897d; Tren Tren Mapu, 2001). Al machitun asisten otros familiares del zorro, como el león (Lincopán, 2017; Painén, 1986a) o integrantes de la comunidad de animales como el ciervo y la cabra de monte (Painén, 1986a) o diversas aves (Salas, 1992c). Pese a estas muestras de solidaridad, el zorro comete nuevas transgresiones. Engaña a las machi y se niega a pagar por los servicios que les ha solicitado y, entonces, muere por segunda vez de modo ejemplar (Tren Tren Mapu, 2001). Trama un ardid en complicidad con el león y se hace el muerto para intentar atrapar al ciervo aprovechando la instancia de la congregación ritual (Painén, 1986a). Tras el machitun, dice que sólo estaba durmiendo, lo que constituye una negación del poder de las machi (Caniuman, 2015). El zorro se muestra así incorregible.

El repertorio incluye variantes que muestran la síntesis aglutinante de segmentos narrativos que pertenecen a diversos relatos-tipo, como los del zorro y su tío el tigre (Lenz, 1895-1897d; Salas, 1992c) o el zorro y el león (Martínez y Loncón, 1999a), lo que analizaremos en el próximo apartado textual. El conjunto presenta, igualmente, algunos textos que escapan al canon previamente referido. En una de las versiones, la zorra va a visitar a un pariente en el cielo, que la mata por su mal comportamiento, la descuera y descuelga a través de un lazo sus restos. Al caer a la tierra la zorra revive por la humedad (Pino, 2017b). En otra versión, el zorro mata al tigre y confecciona con su cuero un lazo que lanza al cielo. Dios jala del lazo para subir al ngürü y luego lo deja caer al vacío (Lenz, 1895-1897d).

El cuento tehuelche analizado (Bórmida y Siffredi, 1969-1970a) presenta, igualmente, un particular esquema narrativo que, no obstante, ofrece conexiones con el universo simbólico mapuche. El narrador no está seguro cómo llega el zorro al cielo, pero presupone que lo ha llevado hasta allí un cisne. En el cielo el zorro interactúa con los habitantes de este espacio, quienes no se alimentan ni defecan, por lo que miran al zorro con curiosidad e inquietud. Estos rasgos corporales constituyen un motivo distintivo de la mitología tehuelche y muestran la incorporación del viaje del zorro al cielo en el universo simbólico local. El cuento termina con la caída del visitante y la aparición de flores en su cabeza tras el golpe en tierra.

El motivo de la «cabeza almácigo» se registra del mismo modo en dos relatos mapuche, donde al zorro le salen flores en la cabeza tras su muerte (Martínez y Loncón, 1999a; Lehmann-Nitsche, 2013a). En uno de ellos (Martínez y Loncón, 1999a), el motivo forma parte de uno de los engaños mapuche, lo que sucede igualmente en un tercer relato (Pino, 2017b). Consultado por las bellas flores que lleva en su cabeza y que causan la admiración de los observadores, el zorro señala a sus interlocutores 
que les han sido plantadas de un golpe. De modo velado señala el ngürü que hay que morir para que florezca la testa. De esta forma acaba con la vida del tigre (LehmannNitsche, 2013a), al que descuera para vestirse con su piel y también mata de este modo a la bandurria (Pino, 2017b), a la que se come.

La representación social subyacente a este motivo es que la cabeza posee fuerza vital y fertilidad, porque se la considera un órgano depositario del espíritu (Moulian y Poblete, 2018). Por lo mismo, los mapuche practicaron la decapitación ritual de sus enemigos y el uso de las cabezas trofeo, como un modo de control anímico de sus contrincantes aun después de muertos. Lo relevante del caso es que los usos rituales y las representaciones de la cabeza son ampliamente compartidas en el mundo amerindio (Arnold y Hastorf, 2008; Tello, 1918; Tonda, 2015). Ellas se encuentran, igualmente, en el registro iconográfico de las culturas paracas (Paul, 2000) y nazca (Conlee, 2007; Proulx, 1999), en cuyo arte rupestre se localizan también las representaciones iconográficas más antiguas de los motivos del viaje del zorro al cielo. Ello deja en evidencia la recurrencia en los motivos simbólicos compartidos en el espacio centro y sur andino.

\section{El zorro y su tío el tigre o león}

Cómo no, el zorro también tiene una importante presencia en las narrativas del Chaco, especialmente entre los grupos toba (Métraux, 1946; Wilbert y Simoneau, 1982 y 1989; Wright, 1988), mocovi (Wilbert y Simoneau, 1988) y wichi o mataco (Métraux, 1939; Terán, 1999). También se registra de modo significativo entre los isoseño guarani del sureste de Bolivia (Ortiz, Mendez, Zarzycki y Alcorn, 2008). Según Métraux (1946, p. 6), este animal «es por lejos el personaje favorito de los narradores toba». En esta cultura corresponde, igualmente, a una figura mitológica relevante (Wright, 1988), a la que se considera poderosa, dotada de capacidad de metamorfosis y a la que se concibe como padre de los chamanes. De similar forma se presenta entre los isoseño, donde «aguara o zorro es el más famoso protagonista en las modernos relatos y mitos» (Ortiz et al., 2008, p. 185). Al igual que en el espacio andino, en el Chaco el zorro desempeña el papel de trickster o embustero. Este carácter se encuentra marcado en la lengua toba, como advierte Wright (1988, p. 22). En ella, el término wagajaga, que designa al zorro, se vincula a la voz nwagajag que significa «mentiroso», caracterizada como «el que ama hacer chistes, hacer bromas a los otros».

Ortiz et al. (2008) señalan que el zorro isoseño es un quebrantador de normas. Métraux (1946, p. 6) caracteriza al personaje toba como «la criatura más colorida, codiciosa, lasciva, jactanciosa y fácil de engañar». Respecto a su destino señala: «por su mal comportamiento o para satisfacer su vanidad se arroja a incontables aventuras que inevitablemente terminan mal para él». Una excepción a esta regla la constituyen los relatos del zorro y el jaguar o yaguareté (Panthera onca), conocido también como 
tigre, que constituyen un motivo frecuente en los repertorios del Chaco. El compendio de literatura originaria de los toba en dos volúmenes de Wilbert y Simoneau (1982, 1989) registra veintiún relatos de este motivo. El volumen dedicado a la literatura originaria mocoví (Wilbert y Simoneau, 1988) presenta otras veintisiete variantes. Manifestaciones del tema se encuentran, igualmente, en textos wichi (Terán, 1999), chorote (Wilbert y Simoneau, 1985) y guaraní (Bareiro, 1980). El personaje burlado y vencido en estas historias, por lo general, es el jaguar o tigre, en tanto, el zorro sale victorioso e impune, respecto a sus transgresiones.

El repertorio chaqueño presenta numerosos elementos de su universo narrativo compartido, que asume un carácter transcultural. Por ejemplo, una de las series de relatos más extendida entre los mocoví (Wilbert y Simoneau, 1988) se estructura en torno a los embates sexuales del zorro hacia la esposa del jaguar. La relación social codificada entre los protagonistas de este corpus narrativo es de filiación directa: el zorro es sobrino del jaguar, que desempeña el rol de tío. La conducta del zorro supone una transgresión a las normas de parentesco y asume un carácter incestuoso. Las tratativas amorosas del zorro hacia la cónyuge del tigre también constituyen uno de los nudos dramáticos de los relatos toba (Wilbert y Simoneau, 1982, 1989) y los wichi (Terán, 1999). La mezquindad del jaguar, que se niega a compartir su alimento con el zorro es otra fuente de conflicto dominante en los relatos toba. Ello también se expresa extensamente en la narrativa folclórica del norte de Argentina. Entre los motivos comunes en el repertorio destaca el uso de una vejiga llena de moscas o abejas para hacer huir al jaguar, la estrategia del jaguar de hacerse el muerto, la prueba de pedos del muerto para descubrir el engaño del jaguar, la trampa del lazo para enfrentar un cataclismo presunto que nunca llega, el refugio del zorro en una cueva, el guardián cegado con un puñado de tierra.

Los elementos de esta gramática narrativa presentan una extensa distribución geográfica y cultural. Los relatos del zorro y el tigre se encuentran ampliamente representados en los repertorios de narrativa folclórica argentina, donde se recopilan en español y con numerosos signos de transculturación narrativa modernizantes, que evidencian su incorporación al imaginario popular. Ellos, por ejemplo, tienen un extenso registro en la suma narrativa de Vidal de Battini (1980), en el repertorio folclórico de Santiago del Estero (Di Lullo, 1943), en los estudios sobre la creación anónima de Canal Feijóo (2010 [1951]), en la compilación de relatos del zorro de Chertudi (1965) y en la selección de relatos populares de Palleiro (1998). La codificación de este tipo de cuentos en lengua quechua sureña se muestra en las narrativas de Santiago del Estero (Andreani, 2014). No obstante, los embustes característicos de su trama literaria se manifiestan, igualmente, en el ciclo del zorro andino, propio del 
área central del Perú y norte de Bolivia. Por lo mismo, Métraux (1946) se pregunta si los temas que alimentan los relatos chaqueños provienen de los Andes, aunque es evidente que el movimiento en algunos casos es a la inversa ${ }^{2}$.

El mismo universo narrativo se hace presente en la cultura mapuche a través de un proceso de transculturación que se manifiesta en diferentes niveles formales. Entendemos que ellos informan de distintos momentos en un continuum progresivo de asimilación: el de la apropiación de las tramas del zorro y el tigre (Panthera onca) y en la incorporación de sus motivos en un ciclo narrativo del zorro y el puma o león (Puma concolor). Respecto a la primera modalidad, que proponemos denominar «transculturación primaria», hemos analizado una serie compuesta de nueve relatos sobre el zorro y su tío el tigre, siete de ellos mapuche (Koessler-Ilg, 1954, pp. 91-95; Lehmann-Nitsche, 2013a, pp. 121-123, 2013c, pp. 161-162; Lenz, 1895-1897b, pp. 189-194, 1895-1897d, pp. 210-219; Sauniere, 1975a, pp. 121-123, 1975b, pp. 123-127) y dos tehuelche (Bórmida y Siffredi, 1969-1970b, pp. 225-226). En relación al segundo grupo de relatos, que distinguimos por su «transculturación secundaria», analizamos un corpus compuesto por catorce epew (Fundación Pehuén, 2001b, sp, 2001c, sp; Kuramochi y Nass, 1993a, pp. 209-216, 1993b, pp. 217-221; Lehmann-Nitsche, 2013b, pp. 129-143; Lenz,1895-1897c, pp. 202-205; Martínez y Loncón, 1999b, pp. 56; Moesbach, 1930a, pp.434-436, 1930b, pp. 436-443; Painén, 1986b, pp. 111-115; Poduje, Fernández y Crochetti, 1993a, pp. 57-63, 1993b, pp. 77-104; Salas, 1992b, pp. 286-289; Slater, 1979b, pp. 161-165). Ambas series muestran una gramática narrativa transcultural compartida, registrada en la literatura amerindia chaqueña y extensamente representada en la literatura folclórica argentina.

En términos referenciales, el protagonismo narrativo del tigre o jaguar (Panthera onca) nos remite a un espacio ecológico externo al Wallmapu, como se denomina al territorio ancestral mapuche, puesto que esta especie no habita en él. El jaguar posee una gran versatilidad adaptativa que le permite sobrevivir en diversos ecosistemas, desde espacios áridos a selváticos de zonas tropicales (Seymour, 1989). En el pasado, es posible que su hábitat se haya extendido hasta el Chubut en la Patagonia Argentina. Si bien, este felino no se localiza en el territorio mapuche, el mapudungun dispone del término nawel, que lo designa. Su nombre se encuentra en la toponimia del Wallmapu, en lugares como la Cordillera de Nahuelbuta («Gran Jaguar») en la Araucanía o la Isla Nahuelhuapi («Isla del Jaguar») en Neuquén, Argentina, lo que plantea interrogantes sobre la posible presencia de esta especie en el pasado. El Chaco y la selva de Salta, Argentina, son los espacios más próximos al territorio mapuche donde hoy todavía se conserva la especie.

2. Entre los motivos característicos de la narrativa chaqueña que se expresan en los Andes se encuentran el matrimonio con la mujer estrella (Métraux, 1939, 1946) y la autoamputación del pene por parte del zorro adúltero, para evitar ser atrapado encajado en su amante (Terán, 1999). 
Un punto relevante para el análisis de la serie narrativa del zorro y el tigre es la procedencia de los relatos. En nuestro repertorio sólo dos de los textos se recopilaron en el Gulumapu, como se denomina el sector occidental de la Araucanía, considerado elárea central de la cultura mapuche, por ser el espacio de difusión y mayor persistencia de la misma. Los relatos se recopilan específicamente en la localidad de Loncoche por Sauniere (1975a, 1975b), pero se registran en castellano. Otros dos textos provienen del Piremapu, área cordillerana, correspondiente al territorio pewenche (Lenz, 18951897b, 1895-1897d). Si bien se transcriben en mapudungun, en ellos, el protagonista felino recibe el nombre de «tipre», lo que indica un préstamo léxico del español en el proceso de transculturación narrativa. Cinco relatos, en tanto, se recolectan el Puelmapu, territorio trasandino oriental, correspondiente al área pampeana de la Patagonia. Tres de ellos son mapuche (Koessler-Ilg, 1954; Lehmann-Nitsche, 2013a, 2013c), dos tehuelche (Bórmida y Siffredi, 1969-1970c y 1969-1970d). En los tres primeros, nawel es el nombre que se le asigna al felino, pero sólo en los textos de Lehmann-Nitsche se registran en mapudungun, lo que indica una escasa circulación de la narrativa del nawel en su lengua originaria.

La situación contrasta respecto al caso de los cuentos del zorro y el león. Diez de los catorce cuentos que hemos compilado proceden del Gulumapu o Araucanía occidental (Fundación Pehuén, 2001b, 2001c; Kuramochi y Nass, 1993a, 1993b; Martínez y Loncón, 1999b; Moesbach, 1930a, 1930b; Painén, 1986b; Salas, 1992b; Slater, 1979b). Siete de ellos se registran en mapudungun. Ello muestra el desplazamiento de este conjunto narrativo hacia el oeste de la cordillera y su incorporación en lo que se considera el área nuclear mapuche, donde este pueblo presenta una mayor concentración de población, arraigo territorial y su cultura tiene un importante grado de conservación y vigencia. El universo narrativo de esta saga expresa una mayor adaptación al universo de referencias locales, lo que informa un proceso de transculturación narrativa secundaria, es decir, una apropiación e incorporación más intensa a la cultura receptora.

Como advierte Slater (1979a), los repertorios de cuentos del zorro y el tigre y del zorro y el león constituyen un ciclo narrativo continuo, porque los relatos presentan una unidad estructural. Según el mismo autor, nos encontramos en él ante la pareja de personajes literarios mejor representados entre los cuentos de animales mapuche. Identificamos dos series narrativas que configuran este ciclo, originadas a partir de distintos nudos dramáticos que se manifiestan, igualmente, en las narrativas del Chaco (Wilbert y Simoneau, 1982, 1988, 1989): la mezquindad del felino, que produce una alianza contrariada, y la lascivia del zorro que genera una transgresión filial. En el primero de los casos, el zorro y el tigre o león constituyen compañeros de caza. Una vez obtenida la presa, el felino es reticente a compartir la carne con su socio, lo que quebranta su alianza y motiva al zorro a urdir un plan para quedarse con la carne o vengarse de su socio. Dentro de un corpus de análisis compuesto por veintitrés 
relatos, nueve se inscriben en esta serie (Fundación Pehuén, 2001b, 2001c; Kuramochi y Nass, 1993a; Lehmann-Nitsche, 2013b; Lenz, 1895-1897c, 1895-1897d; Moesbach, 1930a; Painén, 1986b; Salas, 1992b). En el segundo de los casos, el zorro se siente atraído sexualmente por la esposa del tigre o león y urde un engaño para conseguir su propósito, cometiendo adulterio. Nueve de los relatos conforman esta serie (Bórmida y Siffredi, 1969-1970c, 1969-1970d; Kuramochi y Nass, 1993b; Martínez y Loncón, 1999b; Poduje et al., 1993a, 1993b; Sauniere, 1975a, 1975b; Slater, 1979b). No obstante, al menos un relato más incluye el adulterio como un tema secundario en la trama narrativa (Fundación Pehuén, 2001b), constituyendo éste uno de los motivos literarios más representativo del ciclo, con diez figuraciones.

El ciclo, en su conjunto, plantea el problema de la transgresión a las normas de comportamiento instituidas en el admapu. La relación social preexistente entre los protagonistas es de tío (futa malle) y sobrino (pichi malle), explicitada en dieciséis de los relatos (Bórmida y Siffredi, 1969-1970c, 1969-1970d; Fundación Pehuén, 2001b; Koessler-Ilg, 1954; Kuramochi y Nass, 1993a, 1993b; Lehmann-Nitsche, 2013a, 2013b; Lenz, 1895-1897b, 1895-1897c, 1895-1897d; Martínez y Loncón, 1999b; Painén, 1986b; Salas, 1992b; Sauniere, 1975b; Slater, 1979b). Se trata de una relación de parentesco muy cercana y relevante en la sociedad mapuche, que obliga a prestaciones de asistencia mutua y respeto. La conducta del felino que mezquina a su sobrino el alimento constituye una falta a su deber de reciprocidad. La lascivia del zorro dirigida hacia su tía constituye una transgresión grave a las normas de fidelidad y respeto filial.

En la primera serie, el zorro planea un engaño para quitarle el alimento a su tío felino, lo que genera una persecución de éste en su contra. En la segunda serie, el zorro miente para acceder a los favores sexuales de su tía, la esposa del tigre o león, lo que genera la persecución del felino en búsqueda de venganza de sangre. El común denominador del ciclo narrativo es la confrontación de inteligencia y habilidad entre el felino y el zorro, en la que gana generalmente el cánido. El enfrentamiento incluye trampas, engaños y pruebas de ingenio que se encuentran registrados tanto en la literatura amerindia del Chaco como en los relatos folclóricos del NOA. Todo esto, en contra de las normas propias de la relación de parentesco de sus protagonistas, según los principios del admapu.

Entre los motivos narrativos transculturales presentes en el ciclo destaca la simulación de la muerte. El zorro y el felino emplean exitosamente esta práctica como estrategia de caza (Kuramochi y Nass, 1993a; Lenz, 1895-1897d; Salas, 1992b), a sugerencia del zorro, que llama a los animales a hacerse partícipes del acontecimiento fúnebre. Rota la alianza entre los protagonistas, el tigre o león emplea la misma táctica para tratar de atrapar al zorro (Bórmida y Siffredi, 1969-1970c, 1969-1970d; KoesslerIlg, 1954; Lehmann-Nitsche, 2013b; Lenz, 1895-1897b, 1895-1897c). Éste, por su 
parte, emplea la «prueba de los pedos» para desenmascarar a su persecutor (Bórmida y Siffredi, 1969-1970c, 1969-1970d; Koessler-Ilg, 1954; Lehmann-Nitsche, 2013b; Lenz 1895-1897b). El zorro se niega a acercarse al muerto sin tener una prueba de su deceso. Al respecto, dice que los muertos evacúan gases. Como respuesta, el presunto finado se tira un pedo que lo delata. Otro motivo común es «la trampa del lazo» (Bórmida y Siffredi, 1969-1970c; Koessler-Ilg, 1954; Martínez y Loncón, 1999b; Lenz, 1895-1897b; Sauniere, 1975a). El felino encuentra al zorro buscando lienzas de voqui para amarrarse a un árbol, asegurando la inminente llegada de un gran vendaval. Ante su propia solicitud, el felino es fuertemente amarrado por el zorro, quien aprovecha la oportunidad para azotarlo y lo deja abandonado a su suerte. También forma parte de este repertorio la vejiga llena de moscas (Salas, 1992b). El zorro recibe de su tío la vejiga de una vaca recién carneada para que sacie su hambre. Disconforme con esta alternativa, prefiere inflarla, la llena de moscas para que actúe como caja de resonancia. El zorro ata la vejiga en la cola del tío, mientras éste duerme la siesta, y lo despierta con la advertencia de que se aproximan los cazadores, provocando la huida del tigre. De este modo el zorro se queda con la carne. El ciclo también registra el motivo del guardián cegado (Poduje et al., 1993b). El felino deja a un ayudante vigilando la salida de una cueva donde se ha refugiado el zorro. El zorro lo engaña para echarle tierra en los ojos y poder escapar.

Los motivos previamente referidos configuran episodios y secuencias de enunciados que alimentan los epew, a partir de una gramática narrativa transcultural parcialmente compartida. Algunas de sus unidades expresivas presentan extensa difusión, pero reglas de uso diversas. Los repertorios de motivos, sus patrones de frecuencia y combinación varían en los contextos culturales, otorgando a los ciclos narrativos un carácter particular. Por ejemplo, el motivo de la vejiga con moscas y el del guardián cegado, bastante frecuentes en la narrativa del Chaco (Wilbert y Simoneau, 1982, 1989), presentan respectivamente sólo una aparición en el repertorio mapuche bajo estudio (Poduje et al., 1993b; Salas, 1992b). En contraste, en el ciclo mapuche se encuentran otros motivos ausentes en el Chaco. Es el caso, por ejemplo, del asesinato de los cachorros del felino a manos del zorro, que los echa al interior de una olla hirviendo (Lenz, 1895-1897c; Moesbach, 1930b; Painén, 1986b) y, en un caso, se los da de comer a su madre (Moesbach, 1930b). El tema más próximo en la narrativa chaqueña es el del infanticidio por engaño del zorro, que mata a golpes a sus propios hijos convencido por el armadillo que de este modo obtendrá miel y luego los cachorros volverán mágicamente a la vida (Wilbert y Simoneau, 1988, p. 131). 


\section{Discusión}

La narrativa oral mapuche ha sido considerada un espacio privilegiado de expresión de los valores sociales y contenidos culturales originarios. Dicho de otro modo, las tramas narrativas y motivos literarios de los epew han sido analizados como manifestaciones de una cultura propia y no de una apropiada o transculturada. Así, para hacer inteligibles las transgresiones del zorro a las normas culturales del admapu se ha acudido al análisis de los rasgos del contexto histórico y social del Wallmapu, que ofrecen alternativas para explicar la inconsistencia entre la conducta representada y los códigos evaluativos de referencia.

Sauniere (1975a), por ejemplo, argumenta que el contexto de la guerra anticolonial persistente hace de la astucia y el doblez estrategias aptas para la sobrevivencia, que forjan el carácter mapuche. A nuestro entender, si bien ello permitiría comprender las prácticas de conducta antagónica del zorro hacia el tigre, no explica su actitud ante los códigos sagrados que dan sustento religioso a la propia empresa bélica. La dimensión ritual y espiritual es un componente sustantivo de la guerra de resistencia (Moulian, 2009, 2012). No se entiende, así, que el zorro promueva el empleo de los contextos ceremoniales para las prácticas predatorias, que pase por alto los protocolos de las rogativas que articulan el mundo mapuche o engañe a las machi que le han salvado la vida.

Salas (1992a) aborda los conflictos entre el tío tigre o león y su sobrino el zorro como una expresión de los cambios sociales que se producen en el contexto postreduccional, que imponen un quiebre en los principios de organización del linaje. En contra de esta hipótesis se pueden esgrimir tres tipos de objeciones. En primer término, de carácter temporal, porque Lenz (1895-1897a) registra la transgresión a los códigos de parentesco por parte del zorro en un momento en que el proceso de reducción se encuentra en un estado inicial. En segundo lugar, se puede ofrecer una objeción social: los códigos de parentesco siguen vigentes en el mundo mapuche actual. La familia extensa configura un sistema de relaciones sociales vivo, activo, operante, a través del que se movilizan servicios de apoyo mutuo, asistencia y reconocimiento. La relación entre el futa malle y el pichi malle continúa siendo una de las más importantes dentro de este código. En tercer término, se puede ofrecer una impugnación cultural: Salas ofrece un argumento contingente ante un rasgo del comportamiento del zorro que tiene un carácter estructural. El amplio campo de comportamientos infractores del zorro muestra que éste es constitutivamente un personaje transgresor y no ha devenido circunstancialmente en tal.

Slater (1988) propone un argumento contrastante con el anterior, que el propio Salas (1992a) admite como una hipótesis alternativa a la del cambio social. En esta perspectiva, la oposición entre el tigre o león y el zorro expresa una tensión estructural del sistema de parentesco tradicional mapuche. Para Slater (1988), ello se 
origina en la competencia entre dos sistemas de matrimonio preferente: la selección como esposa de la hija del hermano de la madre o de la hija de la hermana de la esposa, que producen un antagonismo generacional. En cambio, según Salas (1992a), el conflicto narrativo expresa la competencia de intereses por la herencia de los bienes de la madre en caso de fallecimiento del padre, puesto que su hermano (tío / malle) tiene derecho preferente de casamiento con la viuda, absorbiendo los derechos de herencia del hijo. En contraste con el argumento del cambio social, se plantea aquí la vigencia de normas consuetudinarias, que en la práctica ha perdido vigencia. Como sea, se trata de una explicación delimitada, que no permite comprender el carácter transgresor genérico del zorro.

No obstante, como hemos puesto en evidencia, los ciclos narrativos del viaje del zorro al cielo y del zorro y su tío el tigre o león no son propios y exclusivos del mundo mapuche. Se trata de manifestaciones expresivas que tienen un carácter transcultural. Por lo mismo, el análisis de este corpus narrativo en perspectiva particularista resulta limitado y sesgado. En el primero de nuestros casos de estudio, el argumento y los motivos narrativos remiten a las culturas originarias del espacio central andino. En el segundo, a las del Chaco y el folclore del NOA. Las aventuras del zorro siguen aquí planes narrativos compartidos que operan sobre un repertorio común de recursos. Ello incluye los argumentos de los relatos, tanto como episodios y secuencias enunciativas que se organizan a partir de los mismos motivos. Las distintas posibilidades combinatorias de estas unidades expresivas que tienen un carácter preformado y relativa autonomía conforman lo que caracterizamos como una gramática narrativa compartida. Esto no se limita a los casos estudiados. Los cuentos del zorro y la perdiz, donde el primero aprende a silbar, y los relatos de apuestas entre el zorro y el cóndor tienen claros correlatos andinos.

El estudio comparado de los repertorios de relatos del zorro muestra la circulación translingüística y transcultural ampliada de los componentes de su universo narrativo. Como advierte Espino (2014), los cuentos se mueven más que el viento. El zorro transmigra con sus pertenencias y ocurrencias. Su omnipresencia en los sistemas expresivos del Cono Sur muestra esta sorprendente capacidad viajera. La narrativa lúdica, orientada a la entretención, constituye un modo de comunicación socializador, que vincula, despierta interés, concita atención. En el marco de las sociedades ágrafas, la «oralitura» goza de enorme prestigio como un medio de ejercicio de la palabra, que encarna el poder genitivo de la cultura. Los oyentes tienden a repetir las historias y las recrean. La narrativa de entretención es, probablemente, uno de los primeros sistemas de comunicación que asume un carácter transcultural.

Esto no quiere decir que los cuentos analizados no sean parte del patrimonio cultural mapuche. La teoría de la transculturación narrativa enfatiza el proceso creativo de apropiación de elementos culturales ajenos, que son incorporados a la 
propia cultura. Los casos analizados muestran esto con claridad. El corpus del viaje del zorro al cielo expone tanto una contextualización local de los relatos como la transformación de su trama, para instalar en el desenlace un motivo propio, como es el machitun, ritual chamánico que permite resucitar al zorro. Otro tanto sucede en el repertorio del zorro y el león, que evidencia el desplazamiento de los personajes al contexto ecológico mapuche. Evidentemente los relatos proveen contenidos culturales pertinentes y relevantes que sirven a los procesos de socialización. No obstante, se debe ser consciente que muchos de los elementos de su universo narrativo no se han creado en el Wallmapu, sino adaptado a éste. Lo contrario invita a equívocos.

Así, por ejemplo, resulta relevante destacar que la construcción narrativa del zorro como personaje transgresor, tipificado como trickster o embustero, es una constante en los relatos pertenecientes a los diversos contextos culturales comprendidos en este estudio comparativo. Sus textos sitúan al personaje cometiendo el mismo tipo de faltas. Por lo mismo, más que conflictos específicos o problemas locales, la recurrencia en los comportamientos de esta figura devela cuestiones transculturales, es decir, comunes a la experiencia humana en esta región, probablemente un problema universal. Como advierte La Riva (2005), el zorro plantea una tensión entre el plano de las necesidades, impulsos y deseos programados biológicamente y las normas sociales para la administración de los mismos, es decir, el problema de los límites entre la cultura y la naturaleza. Como el problema no tiene solución, no cabe más que procesarlo a través de la risa. Cada vez que enfrentamos a auditores mapuche las alternativas imposibles del comportamiento del zorro, hemos visto el despliegue de una sonrisa en las facciones del rostro. Frente al orden cotidiano dominado por el peso social de las normas, la narrativa emplea el principio terapéutico de la inversión simbólica, que hace triunfar al deseo, para liberar a través de la risa las tensiones que incuba la fuerza represiva de las reglas culturales sobre los impulsos básicos de la vida.

\section{Conclusiones}

Los repertorios de relatos mapuche sobre el viaje del zorro al cielo y del zorro y su tío el tigre o león muestran gramáticas narrativas transculturales, parcialmente compartidas. Ellas nos remiten a la tradición oral de los Andes centrales en el primer caso, al Chaco y al NOA, en el segundo. Tanto el argumento de los relatos, como numerosos motivos que organizan el enunciado de secuencias y episodios forman parte de un universo de contenidos común. En el caso del viaje del zorro al cielo, la representación de los motivos narrativos en el arte rupestre de las culturas paracas y nazca muestran la profundidad histórica de estos relatos en los valles occidentales de la zona centro del Perú, con una data de entre 700 AC y 800 DC. En tanto, la importancia que tienen las figuras del zorro y el jaguar en las narrativas míticas de los pueblos originarios del Chaco, como los toba y wichi, así como de los isoseño guaraní 
del oeste de Bolivia, señalan el origen tropical de la trama del segundo de los casos de estudio.

El proceso de transculturación narrativa que trae estas tramas y sus motivos a la tradición oral mapuche supone un ejercicio creativo, de apropiación transformadora de los contenidos al contexto local. En el caso del ciclo del zorro y el felino, se registran dos estadios en este proceso. En el primero, se verifica la incorporación de la trama del tigre (Panthera onca) y el zorro, que se mantiene vigente en las narrativas del Puelmapu. El segundo, estadio de transculturación, supone la adaptación de la trama a los referentes ecológicos del Gulumapu, por el que la figura del tigre muta a puma león (Puma concolor). En el caso del viaje del zorro al cielo, la transculturación narrativa supone un proceso de refuncionalización de la trama. Mientras en los Andes ésta asume un carácter etiológico, que explica la difusión de las plantas y alimentos, en el Wallmapu se instituye como un relato que afirma el poder chamánico. En este proceso se añaden motivos que organizan episodios y secuencias narrativas que son propias del contexto y le dan al sistema expresivo una fisonomía distintiva. De allí que señalemos que en éste se manifiesta una gramática transcultural parcialmente compartida, puesto que en cada cultura los relatos incluyen elementos diferenciadores tanto en términos de los motivos como en las frecuencias de ellos.

Con todo, el conflicto que plantean las graves faltas del zorro a las normas del admapu no se puede comprender en términos particularistas, puesto que éste rebasa los límites culturales del Wallmapu o territorio mapuche. No nos encontramos aquí con la expresión de una crisis o cuestionamiento del sistema de valores mapuche ni ante la evidencia de una ruptura de su estructura social. El análisis debe tener en cuenta el carácter transcultural de la transgresión como motivo literario que es común al conjunto de las narrativas estudiadas. Esta recurrencia expresa el carácter general del problema: la tensión entre las necesidades básicas, impulsos biológicos y deseos y los códigos sociales que regulan los mismos, estableciendo límites para su administración. El interés universal en torno a esta cuestión explica la circulación ampliada de estos relatos que en todas partes despiertan interés, concitan atención e inquietud. De allí su destino peregrino, transmigrante, políglota, que hace de los cuentos del zorro un tipo narrativo transcultural. Las narrativas del zorro promueven la risa ante las contradicciones de su protagonista, que reflejan la condición humana. Finalmente, las prácticas narrativas amerindias en las que se enuncian estos relatos nos muestran que no cabe más que tomarse con humor una situación tan grave, irresoluble y seria.

Nos alejamos aquí de la imagen de las culturas indígenas como taciturnas, guerreras o religiosas. Los juegos del zorro son expresiones de doble sentido que promueven la risa y se emplean para la diversión, una dimensión íntima de estas culturas poco exploradas que se mantiene plenamente vigente en la actualidad. 


\section{Referencias}

Alegría, Patricia (2014). El tiwula o la ambigüedad en el mundo andino. Revista Boliviana de Investigaciones, 11 (1): 169-194.

Andreani, Héctor (2014). Quichuas, picardias y zorros: Conflictos y tácticas en una comunidad bilingüe. Santiago del Estero: EDUNSE.

Arnold, Denise, Domingo Jiménez y Juan de Dios Yapita (2014). Hacia un orden andino de las cosas. La Paz: Instituto de Lengua y Cultura Aymara.

Arnold, Denise y Christine Hastorf (2008). Heads of state: Icons, power, and politics in the ancient and modern Andes. Walnut Creek: Left Coast Press.

Ayala, José Luis (2002). Literatura y cultura aimara. Lima: Universidad Ricardo Palma.

Bareiro, Rubén (1980). Literatura guaraní del Paraguay. Caracas: Biblioteca Ayacucho.

Bórmida, Marcelo y Alejandra Siffredi (1969-1970a). El zorro sube al cielo». En «Mitología de los tehuelche meridionales. RUNA, 12 (1-2): 225. Doi: https://doi. org/10.34096/runa.v12i1-2.4496.

Bórmida, Marcelo y Alejandra Siffredi (1969-1970b). Mitología de los tehuelche meridionales. RUNA, 12 (1-2): 199-245. Doi: https://doi.org/10.34096/runa.v12i12.4496.

Bórmida, Marcelo y Alejandra Siffredi (1969-1970c). El zorro y el tigre». En «Mitología de los tehuelche meridionales. RUNA, 12 (1-2): 225-226. Doi: https://doi. org/10.34096/runa.v12i1-2.4496.

Bórmida, Marcelo y Alejandra Siffredi (1969-1970d). El zorro y el tigre (2a versión)». En «Mitología de los tehuelche meridionales. RUNA, 12 (1-2): 226. Doi: https:// doi.org/10.34096/runa.v12i1-2.4496.

Canal Feijóo, Bernardo (2010) [1951]. Burla, credo, culpa en la creación anónima. Buenos Aires: Ediciones Biblioteca Nacional.

Caniuman, Natividad (2015). Un entierro en el cielo. En Facebook (página de Mapuche ta Inchi). Recuperado de https://es-es.facebook.com/Mapuchetainchin/photos /a.654127747975899.1073741825.420616444660365/834176326637706/.

Caraballo, Melina (2012). Epew: una forma de relatar la cosmovisión ranquel. Memoria Académica de la Facultad de Humanidades y Ciencias de la Educación de la Universidad Nacional de La Plata. Recuperado de http://www.memoria.fahce. unlp.edu.ar/trab_eventos/ev.3752/ev.3752.pdf.

Conlee, Christina (2007). Decapitation and rebirth: A headless burial from Nasca, Peru. Current Anthropology, 48 (3): 438-445. Doi: https://doi.org/10.1086/517591. 
Chertudi, Susana (1965). Cuentos del zorro. Buenos Aires: Editorial Universitaria.

Di Lullo, Orestes (1943). El folklore de Santiago del Estero. Tucumán: Universidad Nacional de Tucumán.

Espino, Gonzalo (2014). Atuqpacha: memoria y tradición en Los Andes. Lima: Universidad Nacional Federico Villarreal.

Foote, Susan (2012). Pascual Coña. Historia de sobrevivientes: La voz en la letra, la letra en la voz. Concepción: Ediciones Universidad de Concepción.

Fosa, Lydia (2019). Representación geográfica del mito del zorro en el cielo. Estudios Atacameños, 62: 43-70. DOI: http://dx.doi.org/10.22199/issn.0718-1043-20190005.

Fundación Pehuén (2001a). El zorro y el cóndor. En Epeu ngutram mahuida mapu-meu ka eluwma quimun. Relatos de la naturaleza y lo sagrado (sp). Santiago: Firma Gráfica.

Fundación Pehuén (2001b). El zorro y el león. En Epeu ngutram mahuida mapu-meu ka eluwma quimun. Relatos de la naturaleza y lo sagrado (sp). Santiago: Firma Gráfica.

Fundación Pehuén (2001c). Lo que pasó al zorro y el león cerca de un río. En Epeu ngutram mahuida mapu-meu ka eluwma quimun. Relatos de la naturaleza y lo sagrado (sp). Santiago: Firma Gráfica.

Garcilaso de la Vega, Inca (2012) [1609]. Comentarios reales de los incas. Arequipa: El Lector.

Golluscio, Lucía (2006). Socialización poética: los ngïrï epew ('cuentos del zorro'). En El pueblo mapuche: poéticas de pertenencia y devenir, pp.109-132. Buenos Aires: Editorial Biblos.

Guache, Jesús (1995). Avatares de la transculturación. Temas (Nueva Época), 4: 121128. Recuperado de https://www.afrocuba.org/Antol2/Book/Avatares\%20-\%20 JG.pdf.

Itier, César (1997). El zorro del cielo: un mito sobre el origen de las plantas cultivadas y los intercambios con el mundo sobrenatural. Boletín del Instituto Francés de Estudios Andinos, XXVI (3): 307-346.

Itier, César (1999). Karu Ñankunapi: Usi comunidad willakuykunamanta tawa chunka akllamusqay. 40 cuentos en quechua y castellano de la comunidad de Usi (Quispicanchi-Cuzco). Cuzco: CERA Bartolomé de las Casas.

Itier, César (2007). El hijo del oso: La literatura oral quechua de la región de Cuzco. Lima: Instituto Francés de Estudios Andinos.

Jemio, Lucy (2005). Senderos y Mojones: Literatura oral aymara jukumarita. La Paz: Instituto de Estudios Bolivianos, Archivo Oral de la Carrera de Literatura, Universidad Mayor San Andrés. 
Jemio, Lucy (2011). Mitos y cuentos de norte Potosí. La Paz: Archivo Oral de la Carrera de Literatura, Universidad Mayor San Andrés.

Koessler-Ilg, Bertha (1954). Tío nahuel y su primo, el zorro. En Cuentan los araucanos (pp. 91-95). Buenos Aires: Espasa-Calpe.

Kuramochi, Yosuke y Juan Nass (1993a). El león y el zorro. En Los pueblos indios en sus mitos. Mapuche (pp. 209-216). Quito: Abya-Yala.

Kuramochi, Yosuke y Juan Nass (1993b). El zorro y la leona. En Los pueblos indios en sus mitos. Mapuche (pp. 217-221). Quito: Abya-Yala.

La Riva, Palmira (2005). El zorro mutilado, el zorro despedazado. Reflexiones sobre las representaciones de la fertilidad en los Andes meridionales del Perú. En Antoinette Molinié (comp.), Etnografías de Cuzco. Cuzco: Centro Bartolomé de las Casas, Instituto Francés de Estudios Andinos.

Lehmann-Nitsche, Robert (2013a). Cuento del tigre y el zorro. En G. Pozo y M. Canio, Conocimiento e historia mapuche (pp. 121-123). Santiago: Imprenta de LOM Ediciones.

Lehmann-Nitsche, Robert (2013b). Cuento del zorro y el león. En G. Pozo y M. Canio, Conocimiento e historia mapuche (pp. 129-143). Santiago: Imprenta de LOM Ediciones.

Lehmann-Nitsche, Robert (2013c). Cuento del zorro con el tigre. En G. Pozo y M. Canio, Conocimiento e historia mapuche (pp. 161-162). Santiago: Imprenta de LOM Ediciones.

Lehnert, Roberto (2000). Mitos y creencias en el mundo atacameño. Antofagasta: Universidad de Antofagasta.

Lenz, Rodolfo (1895-1897a). Estudios Araucanos. Santiago: Imprenta Cervantes.

Lenz, Rodolfo (1895-1897b). Cuento de un zorro i un tigre. En Estudios Araucanos (pp. 189-194). Santiago: Imprenta Cervantes.

Lenz, Rodolfo (1895-1897c). El zorro, el león y el armadillo. En Estudios Araucanos (pp. 202-205). Santiago: Imprenta Cervantes.

Lenz. Rodolfo (1895-1897d). Cuento del tigre i el zorro. En Estudios Araucanos (pp. 210-219). Santiago: Imprenta Cervantes.

Lincopán, Marta (2017). El zorro que subió al cielo y que revivieron en la tierra. En G. Pozo y M. Canio (eds.), Historias divertidas del mundo mapuche en la memoria de Marta Parra Lincopán (pp. 65-92). Santiago: Ocho Libros.

Martínez, Christian y Elisa Loncón (1999a). El ngillatun en el cielo. En Bío-Bío Wingkul Pewenche epew. Cuentos pewenche del Alto Bío-Bío (pp. 25-27). Temuco: Siedes, Programa de Educación Intercultural Bilingüe Mapuche. 
Martínez, Christian y Elisa Loncón (1999b). El zorro y el león. En Bío-Bío Wingkul Pewenche epew. Cuentos pewenche del Alto Bio-Bío (p. 56). Temuco: Siedes.

Métraux, Alfred (1939). Myths and tales of Matako indian (The Gran Chaco, Argentina). Ethnological Studies, 9: 1-127.

Métraux, Alfred (1946). Myths of Toba and Pilagá Indians of the Gran Chaco. Baltimore: American Folklore Society.

Millington, Mark (2007). Transculturation: Contrapuntual notes to critical orthodoxy. Bulleting of Latin American Research, 26 (2): 256-268. Doi: https://doi. org/10.1111/j.1470-9856.2007.00223.x.

Moesbach, Wilhelm (1930a). La zorra astuta. Primera versión. En Vida y costumbres de los indígenas araucanos en la segunda mitad del siglo XIX (pp. 434-436). Santiago: Imprenta Universitaria.

Moesbach, Wilhelm (1930b). La zorra astuta. Segunda versión. En Vida y costumbres de los indigenas araucanos en la segunda mitad del siglo XIX. (pp. 436-437). Santiago: Imprenta Universitaria.

Morote, Efraín (1988). Aldeas sumergidas: Cultura popular y sociedad en los Andes. Cusco: Centro de Estudios Rurales Andinos Bartolomé de Las Casas.

Morgante, Gabriela (2001). La narrativa animalística y la mitología del trickster en la puna jujeña: la figura del zorro. Anthropologica, 19: 121-146. Recuperado a partir de http://revistas.pucp.edu.pe/index.php/anthropologica/article/view/110.

Moulian, Rodrigo (2012). Metamorfosis ritual: Desde el ngillatun al culto pentecostal. Valdivia: Kultrún y Universidad Austral de Chile.

Moulian, Rodrigo y M. Pía Poblete (2018). Katulongkon: Contextualización y antecedentes transculturales del simbolismo de la cabeza entre los Reche-Mapuche. Estudios Atacameños, 60: 213-239. Doi: http://dx.doi.org/10.4067/S071810432018005001603.

Moulian, Rodrigo (2009). Ailla \& rewe: Mediación ritual de la sociedad mapuche williche. Revista Austral de Ciencias Sociales, 17: 57-74. Doi: doi:10.4206/rev.austral.cienc.soc.2009.n17-04.

Ortiz, Elio, Antonio Mendez, Alejo Zarzycki y Janis Alcorn (2008). Fox Walker on the Parapeti River, Bolivia: The Origins of How We Guarani Live in Íví. En J. Stalle (ed.). Pre-Columbian Landscapes of Creation and Origin (pp. 161-202). New York: Springer.

Ortiz, Fernando (1987) [1940]. Contrapunteo del tabaco y el azúcar. Caracas: Biblioteca Ayacucho.

Painén, Paula (1986a). «El zorro que cayó del cielo». En Sonia Montecino (ed.), El zorro que cayó del cielo y otros relatos de Paula Painén (pp. 101-107). Santiago: Centro de Estudios de la Mujer. 
Painén, Paula (1986b). El zorro y el león. En S. Montecino (ed.), El zorro que cayó del cielo y otros relatos de Paula Painén (pp. 111-115). Santiago: Centro de Estudios de la Mujer.

Palleiro, María Inés (1998). La fiesta en el cielo. Cuentos populares de animales. Buenos Aires: Ediciones del Sol.

Pino, Yolando (2017a). El casamiento en el cielo. En Cuentos mapuche de Chile (pp. 63-64). Santiago: Editorial Universitaria.

Pino, Yolando (2017b). La zorra. En Cuentos mapuche de Chile (pp. 64-65). Santiago: Editorial Universitaria.

Poduje, María Inés, Ana Fernández y Silvia Crochetti (1993a). Cuento del zorro, el león y la leona. En Narrativa ranquel: Los cuentos del zorro (pp. 57-63). Buenos Aires: Talleres Gráficos del Ministerio de Cultura.

Poduje, María Inés, Ana Fernández y Silvia Crochetti (1993b). Cuento del zorro y el león. En Narrativa ranquel: Los cuentos del zorro (pp. 77-104). Buenos Aires: Talleres Gráficos del Ministerio de Cultura.

Paul, Anne (2000). Bodiless human heads in Paracas: Necropolis textile iconography. Andean Past, 6: 69-94. Recuperado de https://digitalcommons.library.umaine. edu/cgi/viewcontent.cgi?article=1092\&context=andean_past.

Proulx, Donald (1999). Nasca headhunting and the ritual use of trophy heads. En J. Rickenbach (ed.), Nasca: Geheimnisvolle Zeichen im Alten Peru (pp.79-87) Zürich: Museum Rietberg Zürich. Recuperado de http://people.umass.edu/ proulx/online_pubs/Nasca_Headhunting_Zurich.pdf.

Radin, Paul (1956). The trickster: A study in American Indian mythology. New York: Philosophical Library.

Rama, Ángel (1974). Los procesos de transculturación en la narrativa latinoamericana. Revista de Literatura Hispanoamericana, 5: 9-38

Rama, Ángel (2008) [1984]. Transculturación narrativa en América Latina. Buenos Aires: Ediciones El Andariego.

Reis, Carlos y Ana Lopes (1996). Diccionario de narratología. Salamanca: Ediciones Colegio de España.

Rubina, Celia (2012). El zorro que cayó del cielo: Motivos etnoliterarios y etiología en la tradición oral quechua. En Proceedings of the 10th World Congress of the International Association for Semiotic Studies (IASS/AIS) (pp. 585-594). La Coruña: Universidad de La Coruña.

Salas, Adalberto (1984). De la etnografía a la literatura, de la literatura a la etnografía. CUSHO, 1 (1): 205-221. DOI: http://dx.doi.org/10.7770/cuhso-V1N1-art137.

Salas, Adalberto (1992a). El mapuche o araucano. Madrid: Editorial Mapfre. 
Salas, Adalberto (1992b). El zorro y el puma. En El mapuche o araucano (pp. 286289). Madrid: Editorial Mapfre.

Salas, Adalberto (1992c). El zorro y la bandurria machi. En El mapuche o araucano (pp. 305-315). Madrid: Editorial Mapfre.

Slater, Fernando (1979a). Análisis estructural del cuento de animales mapuche. Memoria para optar al título de Antropólogo y al grado de Licenciado en Antropología. Concepción: Universidad de Concepción.

Slater, Fernando (1979b). El león, el zorro y el chingue. En Memoria para optar al título de Antropólogo y al grado de Licenciado en Antropología (pp. 161-165). Concepción: Universidad de Concepción.

Slater, Fernando (1988). El zorro se casa: El matrimonio y la narrativa mapuche. En Wenuleufu: El camino al cielo (pp. 101-107). Santiago: Departamento de Estética, Universidad Católica de Chile.

Sauniere, Sperata (1975a). El tigre y el zorro. En Cuentos populares araucanos y chilenos (pp. 121-123). Santiago: Editorial Nascimento.

Sauniere, Sperata (1975b). El tigre, la zorra y el coipu. En Cuentos populares araucanos y chilenos (pp. 123-127). Santiago: Editorial Nascimento.

Seymour, Kevin (1989). Panthera onca. Mammalian Species, 340: 1-9. Doi: https:// doi.org/10.2307/3504096.

Tello, Julio (1918). El uso de las cabezas humanas artificialmente momificadas y su representación en el antiguo arte peruano. Revista Universitaria, 13 (2): 477-533.

Terán, Buenaventura (1999). El ciclo de Tokjuaj. Buenos Aires: Ediciones El Sol.

Tomoeda, Hiroyasu (1982). Folklore andino y mitología amazónica: Las plantas cultivadas y la muerte en el pensamiento andino. Senri Ethnological Studies, 10: 275-306.

Tonda, Daniel (2015). Cabeza trofeo en el mundo andino preincaico. Tradición y cambio (Tesis de grado en Historia). Barcelona: Universidad de Barcelona.

Tren Tren Mapu (2001). Los dos primos. En Conozcamos nuestras raíces a través de los cuentos mapuches, 16-17. Recuperado de www.serindigena.cl/territorios/ recursos/biblioteca/libros/f_cuentos_epew.htm.

Urton, Gary (1981). Animals and astronomy in the Quechua universe. Proceedings of the American Philosophical Society, 125 (2): 110-127. Recuperado de http://nrs. harvard.edu/urn-3:HUL.InstRepos:33703660.

van Kessel, Juan (1993). El tramposo engañado. Revista de Ciencias Sociales, 3: 37-52. Recuperado de http://www.revistacienciasociales.cl/ojs/index.php/publicacion/ article/view/20. 
van Kessel, Juan (1994). El zorro en la cosmovisión andina. Chungará, 26 (2): 236-244.

Recuperado de http://www.chungara.cl/Vols/1994/Vol26-2/El_zorro_en_la_cosmovision_andina.pdf.

Valderrama, Ricardo y Carmen Escalante (1997). El zorro, hijo de Dios. En La Doncella Sacrificada: Mitos del Valle del Colca, (pp. 200-2007). Arequipa: Universidad Nacional San Agustín y Instituto Francés de Estudios Andinos.

Vidal de Battini, Berta (1980). Cuentos y leyendas populares en Argentina. Tomo 3. Buenos Aires: Ediciones Culturales Argentinas.

Vienrich, Adolfo (1999). Azucenas quechua, fábulas quechuas. Lima: Ediciones Lux.

Wilbert, Johannes y Karin Simoneau (eds.) (1982). Folk literature of Toba Indians. Volume One. Los Angeles: UCLA Latin American Center Publications.

Wilbert, Johannes y Karin Simoneau (eds.) (1985). Folk literature of Chorote Indians. Los Angeles: UCLA Latin American Center Publications.

Wilbert, Johannes y Karin Simoneau (eds.) (1988). Folk literature of Mocoví Indians. Volume Two. Los Angeles: UCLA Latin American Center Publications.

Wilbert, Johannes y Karin Simoneau (eds.) (1989). Folk literature of Toba Indians. Volume Two. Los Angeles: UCLA Latin American Center Publications.

Wright, Pablo (1988). Fox steals the catch from tiger. Latin America Indian Literature Journal, 4 (1): 22-41.

\section{Sobre los autores:}

Rodrigo Moulian Tesmer es académico titular de la Facultad de Filosofía y Humanidades de la Universidad Austral de Chile. Doctor en Antropología con mención en Metodologías de la Investigación por la Universidad Complutense de Madrid, Magister en Ciencias de la Comunicación por la Universidad de la Frontera, Antropólogo y Licenciado en Antropología por la Universidad Austral de Chile, Periodista por la Universidad Católica de Chile. Especialista en estudios rituales, ha desarrollado los últimos años una línea de investigación en relaciones interculturales amerindias prehispánicas. Correo Electrónico: rmoulian@hotmail.com. (D) https://orcid.org/00000002-7879-2285

Jaqueline Caniguan Caniguan es académica de la Facultad de Educación, Ciencias Sociales y Humanidades de la Universidad de la Frontera. Candidata al Doctorado en Lingüística por la Universidad de Leiden, Maestra en Lingüística Indoamericana por el Centro de Investigaciones y Estudios Sociales en Antropología (CIESA), Profesora de Lenguaje y Comunicación por la Universidad de La Frontera. Especialista en lingüística del mapudungun, su lengua materna. Poetiza mapuche. Correo Electrónico: jacqueline.caniguan@ufrontera.cl. (D) https://orcid.org/0000-0001-8310-7310 
Gonzalo Espino Reluce es profesor principal de la Facultad de Letras y Ciencias Humanas de la Universidad Nacional Mayor de San Marcos (UNMSM). Doctor y Magister en Literatura Peruana y Latinoamericana por la UNMSM, Maestro en Ciencias Sociales con Mención en Lingüística Andina por FLACSO-Escuela Andina de Postgrado. Especializado en literaturas amerindias y literaturas populares (no canónicas) América Latina. Poeta y crítico literario. Organizador del Encuentro Internacional de Literaturas Amerindias (EILA). Correo Electrónico: gespino@unmsm.edu. pe.cl. https://orcid.org/0000-0001-6685-2212 


\title{
CUHSO
}

Fundada en 1984, la revista CUHSO es una de las publicaciones periódicas más antiguas en ciencias sociales y humanidades del sur de Chile. Con una periodicidad semestral, recibe todo el año trabajos inéditos de las distintas disciplinas de las ciencias sociales y las humanidades especializadas en el estudio y comprensión de la diversidad sociocultural, especialmente de las sociedades latinoamericanas y sus tensiones producto de la herencia colonial, la modernidad y la globalización. En este sentido, la revista valora tanto el rigor como la pluralidad teórica, epistemológica y metodológica de los trabajos.

\author{
EDITOR \\ Matthias Gloël \\ COORDINADORA EDITORIAL \\ Claudia Campos Letelier \\ CORRECTOR DE ESTILO Y DISEÑAdOR \\ Ediciones Silsag \\ TRADUCTOR, CORRECTOR LENGUA INGLESA \\ Aurora Sambolin Santiago \\ SITIO WEB \\ cuhso.uct.cl \\ E-MAIL \\ cuhso@uct.cl \\ LICENCIA DE ESTE ARTÍCULO \\ Creative Commons Atribución Compartir Igual 4.0 Internacional
}

